ARTICLE

DOI: $10.1038 / s 41467-018-07140-x$

\title{
Crystallographic and spectroscopic assignment of the proton transfer pathway in [FeFe]- hydrogenases
}

\author{
Jifu Duan (1) ${ }^{1}$, Moritz Senger ${ }^{2}$, Julian Esselborn', Vera Engelbrecht ${ }^{1}$, Florian Wittkamp ${ }^{3}$, Ulf-Peter Apfel ${ }^{3,4}$, \\ Eckhard Hofmann (10 ${ }^{5}$, Sven T. Stripp (D) ${ }^{2}$, Thomas Happe ${ }^{1} \&$ Martin Winkler $^{1}$
}

The unmatched catalytic turnover rates of [FeFe]-hydrogenases require an exceptionally efficient proton-transfer (PT) pathway to shuttle protons as substrates or products between bulk water and catalytic center. For clostridial [FeFe]-hydrogenase Cpl such a pathway has been proposed and analyzed, but mainly on a theoretical basis. Here, eleven enzyme variants of two different [FeFe]-hydrogenases ( $\mathrm{Cpl}$ and $\mathrm{HydA} 1$ ) with substitutions in the presumptive PT-pathway are examined kinetically, spectroscopically, and crystallographically to provide solid experimental proof for its role in hydrogen-turnover. Targeting key residues of the PTpathway by site directed mutagenesis significantly alters the $\mathrm{pH}$-activity profile of these variants and in presence of $\mathrm{H}_{2}$ their cofactor is trapped in an intermediate state indicative of precluded proton-transfer. Furthermore, crystal structures coherently explain the individual levels of residual activity, demonstrating e.g. how trapped $\mathrm{H}_{2} \mathrm{O}$ molecules rescue the interrupted PT-pathway. These features provide conclusive evidence that the targeted positions are indeed vital for catalytic proton-transfer.

\footnotetext{
${ }^{1}$ Department of Plant Biochemistry, Photobiotechnology, Ruhr-Universität Bochum, 44801 Bochum, Germany. ${ }^{2}$ Department of Physics, Experimental Molecular Biophysics, Freie Universität Berlin, 14195 Berlin, Germany. ${ }^{3}$ Department of Chemistry and Biochemistry, Inorganic Chemistry I, Ruhr-Universität Bochum, 44801 Bochum, Germany. ${ }^{4}$ Fraunhofer UMSICHT, Osterfelder Straße, 346047 Oberhausen, Germany. ${ }^{5}$ Department of Biophysics, Protein Crystallography, Ruhr-Universität Bochum, 44801 Bochum, Germany. Correspondence and requests for materials should be addressed to

T.H. (email: thomas.happe@rub.de) or to M.W. (email: martin.winkler-2@rub.de)
} 
[F eFe]-hydrogenases represent one of natures' most effective classes of redox enzymes catalyzing the reversible reduction of protons to dihydrogen $\left(\mathrm{H}_{2}\right)$ at turnover frequencies of up to $9000 \mathrm{~s}^{-11-3}$. Most [FeFe]-hydrogenases favor proton reduction while [NiFe]-hydrogenases are usually more biased toward $\mathrm{H}_{2}$ oxidation ${ }^{4}$. With their low catalytic overpotential $^{5},[\mathrm{FeFe}]$-hydrogenases represent excellent models for a regenerative and likewise economically feasible $\mathrm{H}_{2}$ production. Their active center ("H-cluster") can be structured into a standard $[4 \mathrm{Fe}-4 \mathrm{~S}]$-cluster $\left([4 \mathrm{Fe}]_{\mathrm{H}}\right)$ and a diiron site $\left([2 \mathrm{Fe}]_{\mathrm{H}}\right)$. The latter is uniquely coordinated by three carbonmonoxide (CO) and two cyanide $\left(\mathrm{CN}^{-}\right)$ligands. They stabilize the cofactor in its protein environment ${ }^{6}$ and fine-tune its redox features ${ }^{7}$. An azadithiolate ligand (adt) further bridges the proximal $\left(\mathrm{Fe}_{\mathrm{p}}\right)$ and the distal $\left(\mathrm{Fe}_{\mathrm{d}}\right)$ iron center, which are differentiated according to their location relative to the $[4 \mathrm{Fe}]_{\mathrm{H}^{-}}$-cluster.

To achieve the extraordinary high turnover frequencies of $[\mathrm{FeFe}]$-hydrogenases ${ }^{8}$, it can be implied that proton transfer (PT) is facilitated by distinct and optimized pathways. PT pathways span large distances through protein scaffolds, e.g. to enable proton-coupled electron transfer or proton translocation ${ }^{9-12}$. They usually comprise of a succession of protonatable or polar residues and protein-bound water molecules aligned at hydrogenbonding distance ${ }^{13,14}$.

Based on the crystal structures of [FeFe]-hydrogenases $\mathrm{CpI}$ from Clostridium pasteurianum and DdH from Desulfovibrio desulfuricans, several putative PT pathways have been discussed $^{15-18}$. Theoretical studies suggest that the most probable PT pathway comprises of strictly conserved residues E282, S319, E279, and C299 (from surface to H-cluster, numbering corresponds to $\mathrm{CpI}$ ), including two protein-bound water molecules (Wat826, Wat1120 4XDC ${ }^{19}$, chain B) located between E279 and C29915,16,20. This pathway ends with C299 located in hydrogenbonding distance to the amine head-group of the adt-ligand. Its identity and importance as a proton relay was verified in comparative studies on cofactor variants of HydAl from Chlamydomonas reinhardtii ${ }^{21}$. Cornish and co-workers could show that amino-acid substitutions along the putative PT pathway dramatically decreased the catalytic activities. In particular, their study indicated a participation of surface-exposed residue E282 in catalytic $\mathrm{PT}^{15}$. In a second study they suggested a regulative function for positions R286 and S320 in the PT of $\mathrm{CpI}^{22}$. Furthermore, Morra and co-workers described that the $\mathrm{pH}$ optimum of variant $\mathrm{C} 298 \mathrm{D}$ of $[\mathrm{FeFe}]$-hydrogenase $\mathrm{CaI}$ from Clostridium acetobutylicum (corresponding to C299D in CpI) is shifted from $\mathrm{pH} 8$ to $\mathrm{pH} 7$, indicative for the involvement of $\mathrm{C} 298$ in $\mathrm{PT}^{23,24}$.

Although several studies were conducted, immediate experimental evidence for the relevance of residues in the putative PT pathway is missing, leaving an essential aspect of enzymatic performance opaque. In this study, site-directed mutagenesis (SDM) is used to investigate the PT pathway of two [FeFe]hydrogenases, namely CpI and HydA1, which represent the largest (M3) and smallest (M1) type of monomeric [FeFe]-hydrogenases, respectively ${ }^{25}$. Most of the 22 SDM variants show strongly affected $\mathrm{H}_{2}$ release activities and $\mathrm{pH}$ optima. For 11 of these variants the crystal structure is solved, which facilitates a correlation of individual structural features (i.e. hydrogenbonding distances) and catalytic performance. This provides insight into the minutiae of PT on the molecular level. Catalytically hampered SDM variants are analyzed by in situ attenuated total reflection Fourier transform infrared (ATR-FTIR) spectroscopy. When flushed with $\mathrm{H}_{2}$, these enzymes are found to adopt a key intermediate of hydrogen turnover, the recently described $\mathrm{H}_{\text {hyd }}$ state ${ }^{26-30} . \mathrm{H}_{\text {hyd }}$ accumulation under $\mathrm{H}_{2}$ clearly correlates with the diminished PT efficiency of the enzyme ${ }^{29}$. Herein we provide complementary kinetic, structural, and spectroscopic data, which allow to verify the PT pathway discussed above as the key route of catalytic PT in $[\mathrm{FeFe}]$-hydrogenases.

\section{Results}

$\mathrm{H}_{2}$ release assays and $\mathrm{pH}$-dependent enzyme activities. For both CpI and HydA1, 11 SDM variants were generated to target residues along the putative PT pathway applying conservative and non-conservative exchanges (Fig. 1). Conservative exchanges (e.g. $\mathrm{E} \rightarrow \mathrm{D}$ ) maintain the functional group of the targeted position, but due to other structural differences in the substitute residue, will affect the precise spatial placement and configuration of the functional group. In a highly ordered system such as the welldistanced H-bond chain of an evolutionarily optimized PT pathway, this should at least affect the efficiency of the functional aspect. Non-conservative exchanges (e.g. $\mathrm{E} \rightarrow \mathrm{Q} / \mathrm{A}$ ) delete the functional group entirely and therefore prohibit these substitute residues from rescuing the targeted function. For wild-type (wt) enzyme, $\mathrm{H}_{2}$ release activities of about 860 (HydA1) and 2600 (CpI) $\mu \mathrm{mol} \mathrm{H}_{2}$ per mg per min were measured and defined as $100 \%$ activity ${ }^{29,31-33}$. Corresponding substitutions in CpI and HydA1 had similar effects on $\mathrm{H}_{2}$-release activity, except for variants $\mathrm{E} 282 \mathrm{Q}_{\mathrm{CPI}}(8.2 \%)$ and $\mathrm{E} 144 \mathrm{Q}_{\mathrm{HydA} 1}(0.4 \%)$. The strongest impacts were achieved when replacing E279 $\mathrm{CpI}$ for A or Q, or C299 $\mathrm{CpI}$ for A or S, resulting in activities $<1 \%$. This is well in line with the overall trend of an increasing impact of substitutions along the PT pathway in the direction from surface to $\mathrm{H}$-cluster with C299D being the only exception (Fig. 1b). In general, conservative amino-acid exchanges had less dramatic effects than non-conservative substitutions. However, in some cases a nonconservative exchange to alanine retained a surprisingly large fraction of activity. Variants E282 $\mathrm{D}_{\mathrm{CpI}}, \mathrm{C} 299 \mathrm{D}_{\mathrm{CpI}}, \mathrm{R} 286 \mathrm{~A}_{\mathrm{CpI}}$, and E282 $\mathrm{A}_{\mathrm{CPI}}$ were only mildly affected and showed residual activities between 30 and $90 \%$. For the same PT pathway position, different substitutions can have a dramatically different impact as exemplified by position $\mathrm{E} 144_{\mathrm{HydA} 1} / \mathrm{E} 282_{\mathrm{CPI}}$. Here the exchange to glutamine diminished enzyme activity to only $0.4-8 \%$, while the non-conservative exchange to alanine and the conservative exchange to aspartic acid retained between 46 and $81 \%$ activity. Further, there is a general trend for substitutions of the more surface-exposed PTP positions (R286, E282, and even S319) in $\mathrm{CpI}$ to have slightly lower impact on enzymatic activity as compared to the corresponding HydA1 variants. It might suggest for CpI a more open or flexible access to the PT pathway, which can tolerate variations slightly better than HydAl. This is especially obvious in the light of the 20 -fold difference in the relative activity of $\mathrm{E} 282 \mathrm{Q}_{\mathrm{CpI}}$, as compared to its HydAl counterpart E144Q.

To link the role of individual residues in the putative PT pathway to substrate/product $\left(\mathrm{H}^{+}\right)$transfer, we probed the $\mathrm{pH}$ activity profiles of variants with a high enough level of residual activity in terms of $\mathrm{H}_{2}$-release and $\mathrm{H}_{2}$-oxidation activity. As shown in Fig. 2a, native HydA1 is most active from $\mathrm{pH} 7$ to $\mathrm{pH} 8$ while wild-type $\mathrm{CpI}$ (Fig. 2b) clearly reaches its highest activity at about $\mathrm{pH}$ 8. Variant CpI-Y572A served as a negative control, with an amino-acid substitution outside of the putative PT pathway and features the $\mathrm{pH}$-dependency profile of wild-type enzyme (see Supplementary Fig. 2a). In contrast to this behavior, the $\mathrm{pH}$ optima of all variants targeting the putative PT pathway were shifted to lower $\mathrm{pH}$ values, indicating that the limited PT efficiency can at least be partially rescued by an increased proton concentration.

Just as observed for catalytic activity, different variants of the same position in the putative PT pathway can cause significantly deviating shifts in $\mathrm{pH}$ optimum. In case of $\mathrm{E} 282_{\mathrm{CpI}}$, a substitution for aspartic acid shifted the optimum only slightly to $\mathrm{pH} 7.5$ while 


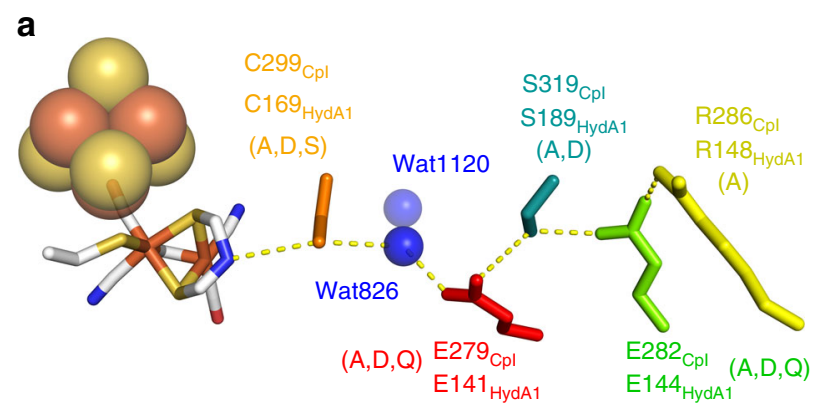

b

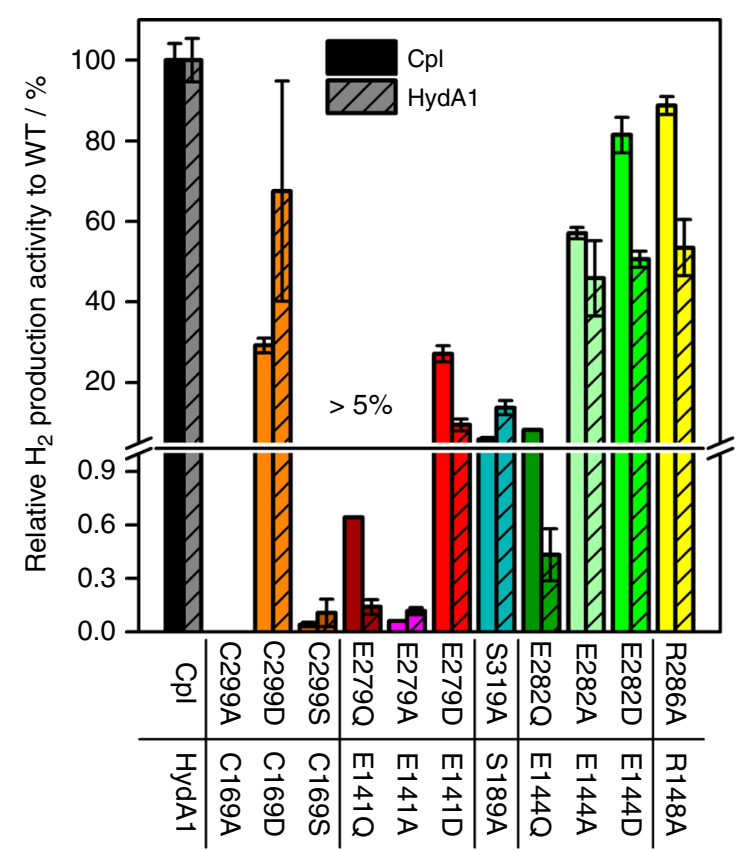

Fig. 1 Putative PT pathway in $\mathrm{Cpl}$ and $\mathrm{H}_{2}$ evolution activities of SDM variants. a The PT pathway of $\mathrm{CpI}\left(\mathrm{PDB}: 4 \mathrm{XDC}^{19}\right)$ is presented as stick structure with individually colored residues while the [4Fe-4S]-cluster and water molecules are shown as spheres. The substitutions applied in this study for individual positions are shown in parentheses below the respective position labels. $\mathbf{b} \mathrm{H}_{2}$-production activity of SDM variants targeting the putative PT pathway in $\mathrm{Cpl}$ and $\mathrm{HydA} 1 . \mathrm{H}_{2}$ production activities of PT pathway variants determined at $\mathrm{pH} 6.8$ are presented in \% relative to the respective wild-type activity. Activity bars for different variants of the same position exhibit corresponding basic colors but different shades. Relative activities higher than $5 \%$ are shown in the upper part of the discontinuous scale. Wild-type $\mathrm{Cpl}$ and $\mathrm{HydA} 1$ exhibit activities of $2576 \pm 107$ and $862 \pm 46.5 \mu \mathrm{mol} \mathrm{H}_{2}$ per mg per min, respectively. The bars represent mean values from at least three independent measurements, including standard deviations. Details on the in vitro assay are presented in Supplementary Fig. 1

an exchange to alanine or glutamine rendered the enzyme most active at $\mathrm{pH} 7$ and 6 , respectively (Fig. $2 \mathrm{~b}$ ). In most cases, the extent of the shift correlates to an overall loss in $\mathrm{H}_{2}$ release activity, however this has not been observed in all cases. The conservative variant E279D retains $10-30 \%$ of $\mathrm{H}_{2}$ release activity but exhibits a significantly stronger down-shift in $\mathrm{pH}$ optimum than the largely inactive variant E279Q (Fig. 2c). As shown in Fig. 2 and Supplementary Fig. 2, no significant differences between $\mathrm{CpI}$ and HydA1 and their respective SDM variants were observed, underlining the universal impact of the putative PT pathway. To probe the relevance of the putative PT pathway for catalytic proton release, we also investigated the $\mathrm{pH}$-dependency of $\mathrm{H}_{2}$ oxidation. It is known from electrochemistry experiments with different $[\mathrm{FeFe}]$-hydrogenases that the enzyme exhibits an increasing $\mathrm{H}_{2}$-oxidation rate with increasing buffer $\mathrm{pH}^{6}$. Accordingly, the $\mathrm{pH}$ range used in this assay was extended to $\mathrm{pH}$ 10. As shown in Supplementary Fig. 3, $\mathrm{H}_{2}$-uptake activity of native HydAl generally enhanced with decreasing $\mathrm{H}_{3} \mathrm{O}^{+}$ concentrations, exhibiting a nearly fivefold rate-increase per $\mathrm{pH}$ unit between $\mathrm{pH} 6$ and 8 . After an intermediate drop between $\mathrm{pH}$ 8 and 9 the $\mathrm{H}_{2}$-oxidation activity further increased to nearly $20.000 \mu \mathrm{mol} \mathrm{H}_{2}$ per mg per min between $\mathrm{pH} 9$ and 10. The absolute activities of SDM variants were significantly diminished compared to wild-type $\mathrm{HydA} 1$, reaching a $\mathrm{pH}$ optimum of at best 6\% (R148A). Up to $\mathrm{pH} 9$, variant $\mathrm{R} 148 \mathrm{~A}_{\mathrm{HydA} 1}$ showed a wildtype-like trend for the $\mathrm{pH}$-activity profile of relative $\mathrm{H}_{2}$-oxidation activity, while instead of a second increase between $\mathrm{pH} 9$ and 10, the activity strongly declined, suggesting that this second increase is connected with the titration of the guanidine base of R148. The $\mathrm{pH}$-activity profile of $\mathrm{E} 144 \mathrm{~A}_{\mathrm{HydA} 1}$ was quite similar to wild-type HydA1, despite a flattening out of the local maximum at around $\mathrm{pH}$ 8. The latter suggests that this local activity maximum is depending on the presence of the surface-exposed Glu residue. S189A and C169D only showed single activity peaks at $\mathrm{pH} 8$ or 9 , respectively with very low $\mathrm{H}_{2}$-uptake rates of $1-2 \%$, compared to wild type.

Infrared spectroscopy. We recently showed that decreased proton release efficiency in the presence of $\mathrm{H}_{2}$ leads to an accumulation of the hydride state, $\mathrm{H}_{\text {hyd }}{ }^{29}$. This H-cluster intermediate carries a terminal hydride and represents the first catalytic intermediate after heterolytic cleavage of $\mathrm{H}_{2}{ }^{26-29}$. In previous studies we exploited this behavior to demonstrate that positions $\mathrm{C} 169_{\mathrm{HydAl}} / \mathrm{C} 299_{\mathrm{CpI}}$ and $\mathrm{E} 141_{\mathrm{HydAl}} / \mathrm{E} 279_{\mathrm{CPI}}$ contribute to catalytic $\mathrm{PT}^{29}$. Non-conservative substitutions to alanine that interrupted the PT pathway led to an enrichment of $\mathrm{H}_{\text {hyd }}$ instead of adopting a mix of reduced redox species (see below). Here this approach was applied to link PT activity of residues in the putative PT pathway to the steady-state equilibrium of redox species in the presence of $\mathrm{H}_{2}$. Employing ATR-FTIR spectroscopy, we probed $\mathrm{CpI}$ and HydA1 wild-type protein and the respective SDM variants at $\mathrm{pH} 8$ under either $\mathrm{N}_{2}$ or $\mathrm{H}_{2}$ (Fig. 3). When flushed with $\mathrm{N}_{2}$, autooxidized HydA1 wild type and SDM variants uniformly exhibit peaks around 1964, 1939, and $1802 \mathrm{~cm}^{-1}$ characteristic for the $\mathrm{H}_{\text {ox }}$ state $^{34}$. HydA1 and CpI wild-type enzymes adopt a mixture of reduced states when exposed to $\mathrm{H}_{2}$, predominantly $\mathrm{H}_{\text {red }} / \mathrm{H}_{\text {sred }}$ and $\mathrm{H}_{\text {red }}{ }^{34,35}$. In contrast, most variants populate the $\mathrm{H}_{\text {hyd }}$ state that can be enriched in wild-type enzyme only at $\mathrm{pH} 4$ (see Supplementary Fig. 4). Similar results were achieved for the corresponding variants of $\mathrm{CpI}$ as shown in Fig. $3 \mathrm{c}$, d. HydA1 variants C169D, S189A, E144D, and R148A, as well as corresponding CpI variants show wild-type-like spectra by adopting a mixture of reduced states instead of $\mathrm{H}_{\text {hyd }}$ (Fig. 3b). With the exception of $\mathrm{S} 89 \mathrm{~A}_{\mathrm{HydA} 1} / \mathrm{S} 19 \mathrm{~A}_{\mathrm{CpI}}$, these variants retain a higher level of $\mathrm{H}_{2}$ release activity (Fig. 1b), which explains why in these cases $\mathrm{H}_{\text {hyd }}$ cannot be trapped at $\mathrm{pH} 8$; just as wild-type enzyme, these variants populate $\mathrm{H}_{\text {hyd }}$ when titrated to significantly lower $\mathrm{pH}$ values (Supplementary Fig. 4). Interestingly, variant C169D and the corresponding variant of $\mathrm{CPI}$ (C299D) seem to be incapable of accumulating $\mathrm{H}_{\text {hyd }}$ under any of the conditions applied here.

Protein crystallography. For eight $\mathrm{CpI}$ variants (holoenzyme) and three HydAl variants (apo-enzyme) protein crystals were obtained. Their structures were solved and refined to resolutions of $1.45-2.76 \AA$, allowing us to gain insight into the structural consequences of SDM. Corresponding to earlier crystal structure data, for all CpI variants a space group of P1 $2_{1} 1$ was observed with two copies in the asymmetric unit cell (chain A and B) $)^{19,25}$. 
a
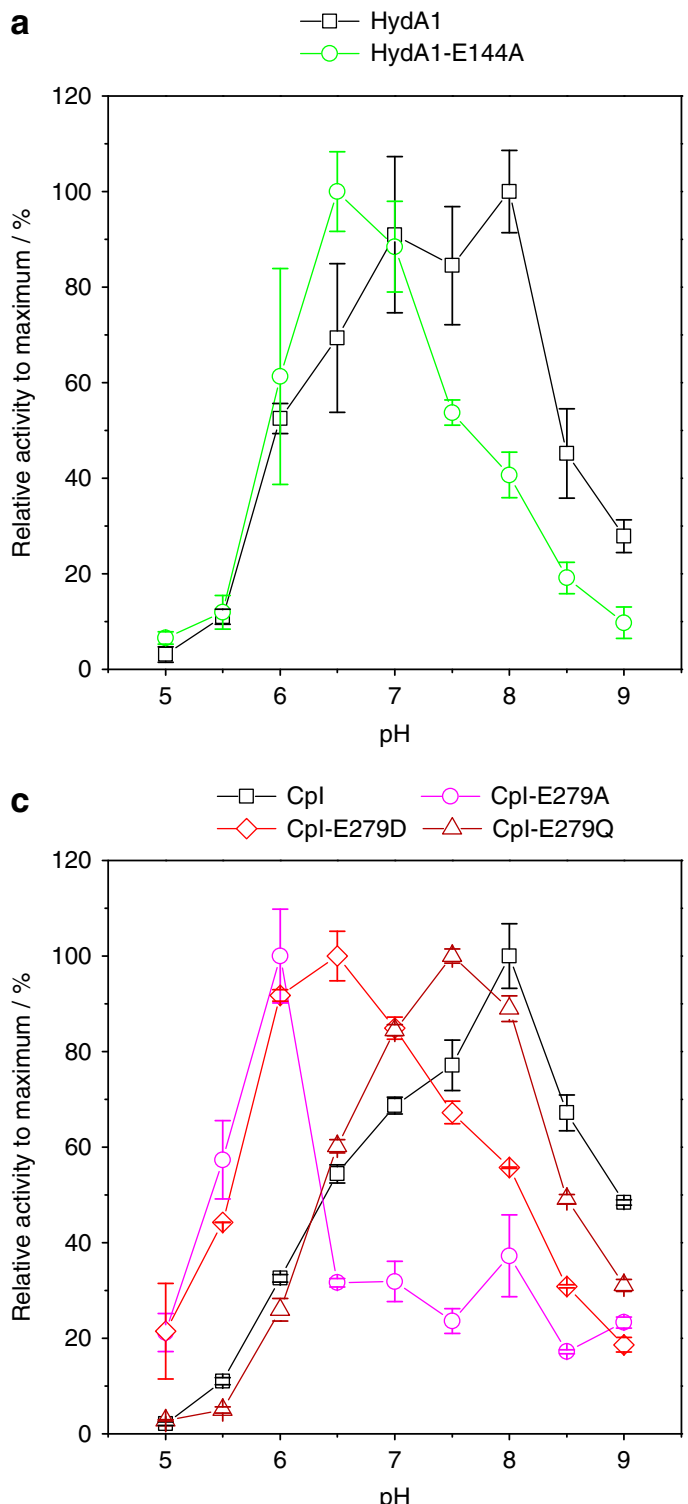

b
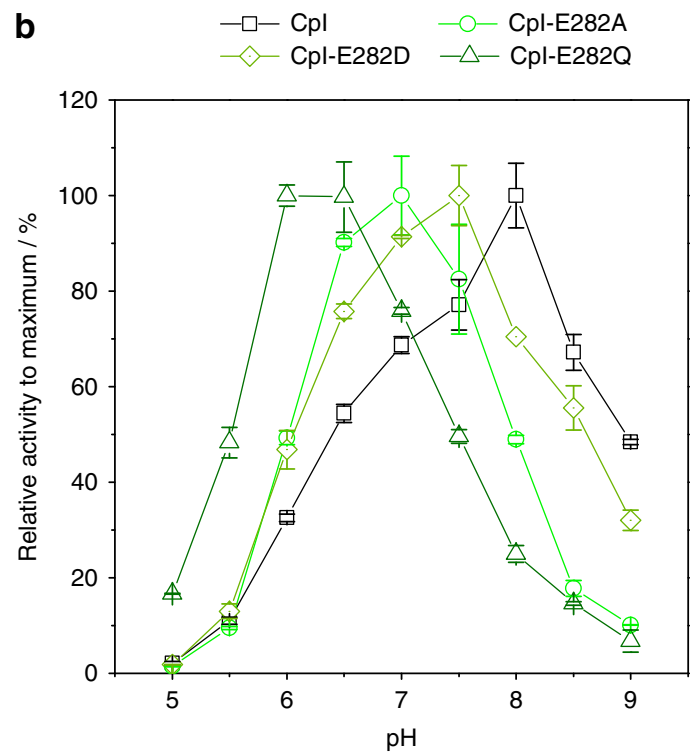

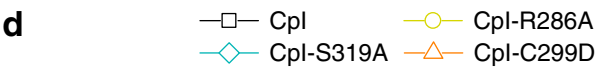

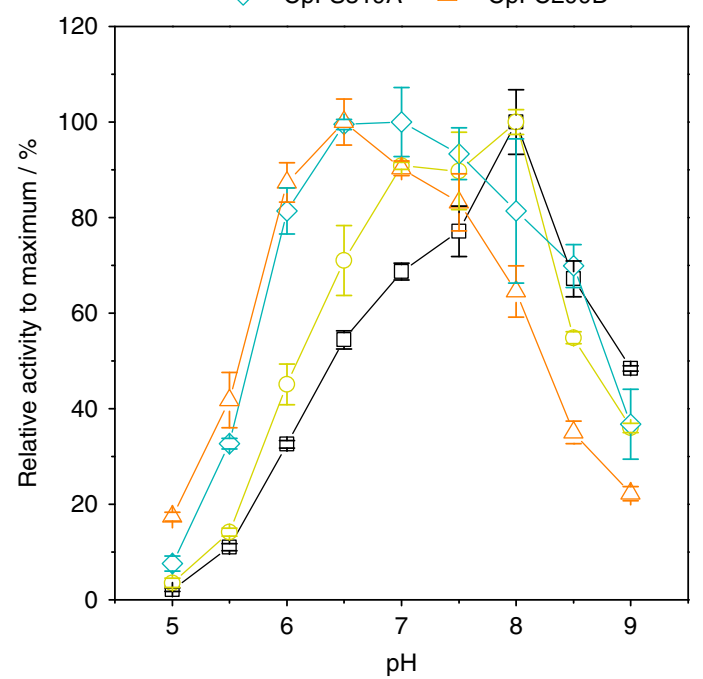

Fig. $2 \mathrm{pH}$-activity profiles of wt-Cpl and wt-HydA1 compared to selected SDM variants. a HydA1 and E144A; b wt-Cpl and variants of position E282; c wt$\mathrm{Cpl}$ and variants of position E279; $\mathbf{d}$ wt-Cpl and selected variants of positions R286, S319, and C299. $\mathrm{H}_{2}$ production activities were determined for different buffers, covering a pH gradient between 5 and 9 in steps of $0.5 \mathrm{pH}$ units. Relative values correspond to \% of maximum activity obtained throughout the entire $\mathrm{pH}$ gradient. Black plots indicate the relative $\mathrm{pH}$-dependent activities of $\mathrm{Cpl}$ and HydA1 wild-type enzymes. All values are mean values \pm standard deviations from at least three independent measurements

Crystallization of HydA1 exclusively succeeded for apo-protein, which carries the $[4 \mathrm{Fe}]_{\mathrm{H}^{-}}$-cluster but lacks the $[2 \mathrm{Fe}]_{\mathrm{H}^{-}}$site $(\mathrm{Sup}-$ plementary Fig. 5). However, comparisons of crystal structures of CpI apo- and holo-protein with apo-HydA1 demonstrated that a lack of cofactor does not affect the configuration of the putative PT pathway ${ }^{19,36}$. Variants of HydA1 apo-protein were crystallized in space group $\mathrm{P}_{2} 21$, with a single chain in the asymmetric unit. Overall, SDM did not induce unspecific structural changes as deduced from superposition with wild-type enzyme and corresponding root-mean square deviations of $\mathrm{Ca}$ atoms (Supplementary Table 2) and the the $\mathrm{H}$-cluster was largely present for all CpI variants (Supplementary Table 5).

In the following, local structural changes in the putative PT pathway will be described. We start from the surface-exposed residues $\mathrm{R}_{286_{\mathrm{CPI}}}$ and $\mathrm{E} 282_{\mathrm{CpI}}$, will continue addressing the median positions $\mathrm{S} 319_{\mathrm{CpI}}$ and $\mathrm{E} 279_{\mathrm{CpI}}$, and end with $\mathrm{C} 299_{\mathrm{CPI}}$ in the vicinity of the H-cluster.
According to their close inter-residue distance of $2.8 \AA$, $\mathrm{R} 286_{\mathrm{CpI}}$ may function as a salt bridge partner of deprotonated E282 $\mathrm{CpI}$ (Fig. 4, right and Supplementary Figs. 6, 7) and thus could be involved in the PT mechanism. R286 $\mathrm{CpI}$ is further part of an extensive hydrogen-bonding network, which includes the carboxyl group of $\mathrm{E} 282_{\mathrm{CpI}}$, histidine residues $\mathrm{H} 565_{\mathrm{CpI}}$ and $\mathrm{H} 569_{\mathrm{CpI}}$, and surface-bound $\mathrm{H}_{2} \mathrm{O}$ molecules. In case of variant R286A significantly fewer water molecules are observed in the same region (Supplementary Fig. 8). We therefore assume that the loss of the guanidine group in R286A destabilizes the network of proton-accepting/donating surface-bound $\mathrm{H}_{2} \mathrm{O}$ molecules near the entrance to the PT pathway. However, as the essential chain of PT pathway residues is not directly affected, the influence of this exchange on catalytic activity is comparatively weak (Fig. 1b).

In E282A, two water molecules occupy the space of the missing carboxylic acid group (chain B, Wat717 and Wat974) (Fig. 4, top middle and Supplementary Fig. 13a). The distances between these 

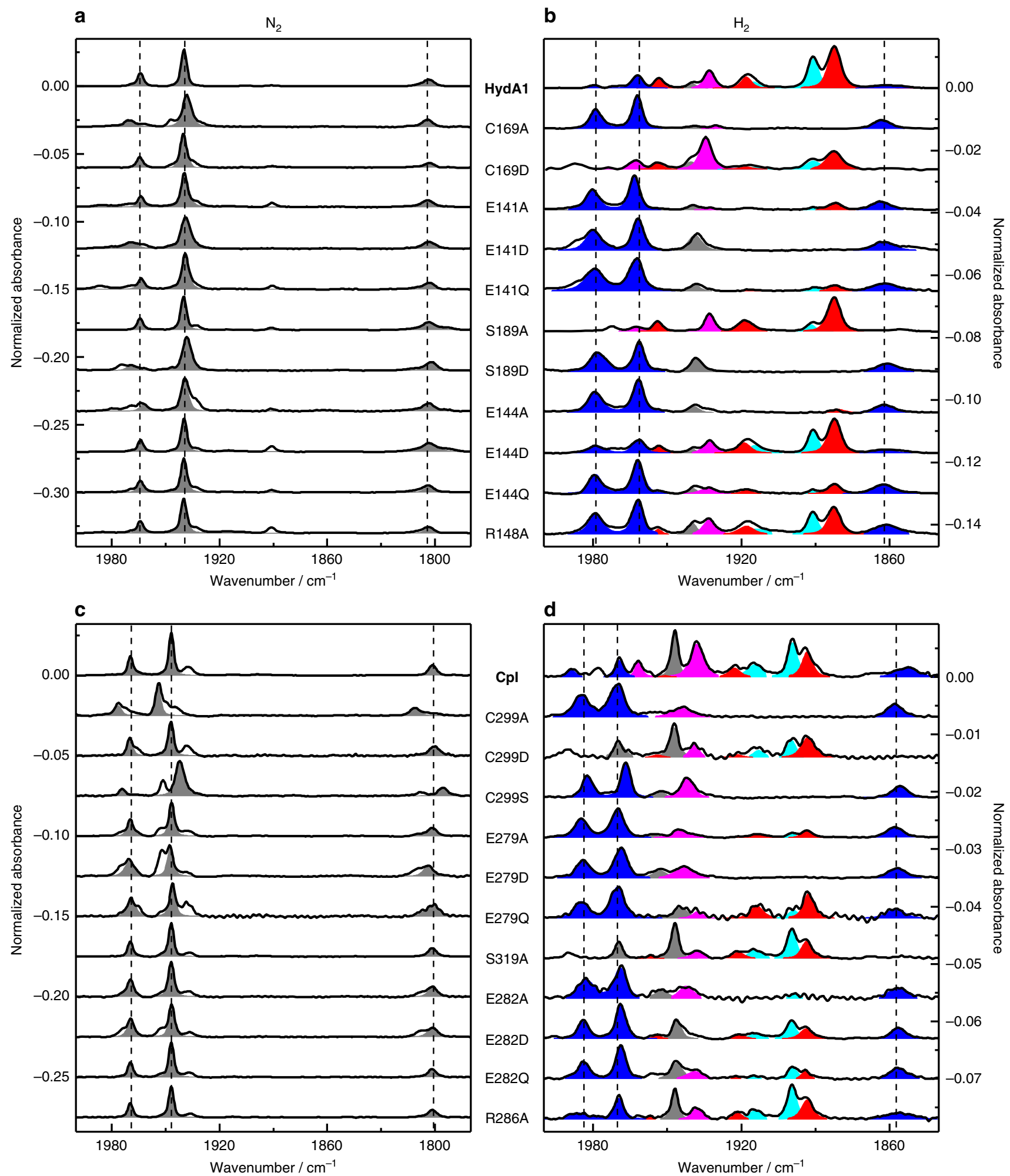

Fig. 3 Infrared spectra of wild types and PT pathway variants. The frequency regime of the H-clusters' CO ligands is shown (2000-1785 $\left.\mathrm{cm}^{-1}\right)$. For ATRFTIR spectroscopy, the buffer was set to $\mathrm{pH} 8$ and the rehydrated samples were purged with $100 \% \mathrm{H}_{2}$ for 5 min. a, c Auto-oxidation in absence of $\mathrm{H}_{2}$ (i.e. purged with $\mathrm{N}_{2}$ ) was exploited to likewise enrich for all examined proteins the oxidized resting state, $\mathrm{H}_{\mathrm{ox}}$ (gray bands). Some Cpl variants tend to accumulate $\mathrm{H}_{\text {ox }} \mathrm{H}$ in parallel with $\mathrm{H}_{\text {ox }}$ (e.g. C299A bands at frequencies 1975/1953/1809) ${ }^{34}$. b, d When shifting from $\mathrm{N}_{2}$ to $\mathrm{H}_{2}$ the spectrum of wild-type protein changes to different fractions of reduced species including $\mathrm{H}_{\text {red }}$ (cyan) and $\mathrm{H}_{\text {sred }}$ (red) as well as $\mathrm{H}_{\text {red }}$ ' (magenta). Most PT pathway variants accumulate $\mathrm{H}_{\text {hyd }}$ (blue) instead or in addition to a mix of reduced states. For precise state-specific vibrational signals of $\mathrm{Cpl}$ and $\mathrm{HydA} 1 \mathrm{see}$ Supplementary Table 7 


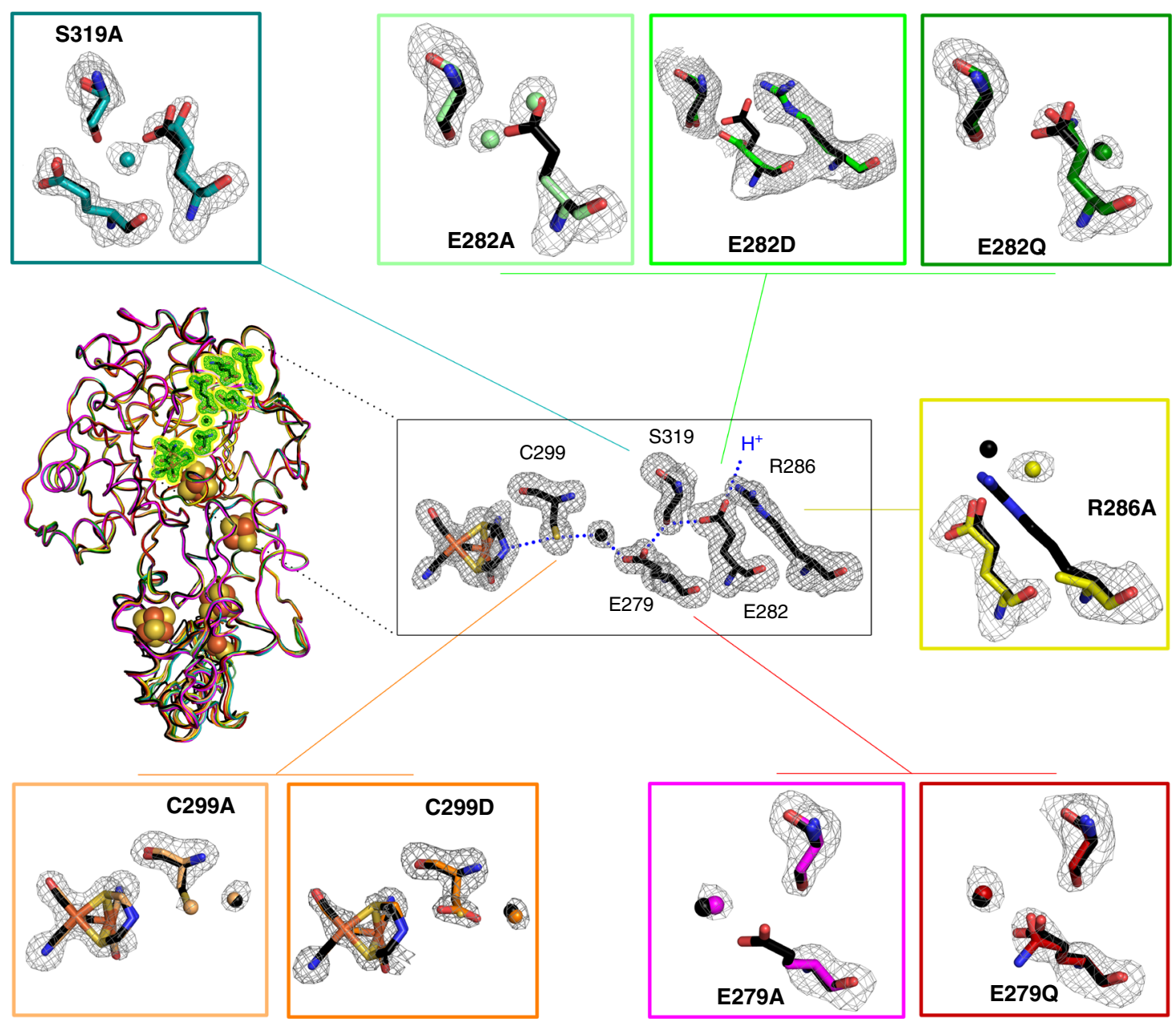

Fig. 4 Structural features of SDM variants targeting the putative PT pathway in Cpl. Structures of nine SDM variants are superimposed as cartoon-loop models together with the $4 X D^{19}$ wild-type structure. No unspecific differences are observed. For each variant an enlargement of its electron density map in the putative PT pathway and the corresponding sticks model has been aligned with the structure of wild-type protein $\left(\mathrm{H}_{2} \mathrm{O}\right.$ molecules and carbon atoms colored in black). For the $\mathrm{Cpl}$ proteins local structural differences near the site of mutagenesis are depicted (for the HydA1 variants see Supplementary Fig. 5). Simulated annealing omitting maps $\left(F_{\mathrm{o}}-F_{\mathrm{c}}\right)$ were contoured at $3 \sigma$ except for E282D, which was contoured at $1.9 \sigma$ due to its comparatively low resolution. Chain $\mathrm{B}$ provides a more flexible $\mathrm{N}$ terminus but a more rigid $\mathrm{H}$-domain where both the PT pathway and the active center are located ${ }^{19}$.

Therefore, all the structural information of $\mathrm{Cpl}$ was derived from chain $\mathrm{B}$ if not stated otherwise

water molecules and the hydroxyl group of S319 are 2.5 and $3.1 \AA$ (see Supplementary Fig. 7), respectively. They are close enough to rescue the PT activity between surface water and $\mathrm{S} 319_{\mathrm{CpI}}$ further downstream the PT pathway. In the crystal structure of apoE144A $\mathrm{A}_{\mathrm{HydA} 1}$, one water molecule remains in a very similar position (Supplementary Fig. 5). It is therefore not surprising that both variants exhibit $50 \%$ wild-type activity (Fig. 1 ). In variant $\mathrm{E} 282 \mathrm{Q}_{\mathrm{CpI}}$, the glutamine residue is potentially stabilized by two hydrogen bonds (H-bonds) unrelated to the putative PT pathway thus, blocking PT and rendering the enzyme largely inactive (Supplementary Fig. 7). Additionally, the two different conformations of Q282 $\mathrm{CpI}$ in chain A and B (Supplementary Fig. 7) indicate structural flexibility at the entrance of the PT pathway, which may support the residual activity measured for this variant.

In variant $\mathrm{S} 319 \mathrm{~A}_{\mathrm{CpI}}$, the carboxyl group of $\mathrm{E} 282_{\mathrm{CpI}}$ is slightly shifted outward, probably due to the lack of the hydroxyl group at position $319_{\mathrm{CpI}}$. In wild-type enzyme $\mathrm{S} 319_{\mathrm{CpI}}$ acts as H-bond donor to $\mathrm{E} 282_{\mathrm{CpI}}$ and drags its carboxy group further into the PT pathway (Fig. 4). In S319A $\mathrm{A}_{\mathrm{CPI}}$ an unprecedented water molecule (Wat735) is located between E282 and A319, and the nearby water molecule Wat873 of wild-type CpI (chain B) is missing here, suggesting a translocation enabled by the unoccupied space of the missing hydroxyl group of position 319 and the slight outward shift of E282 (see Supplementary Fig. 12c). Although the distance to the carboxyl group of E279 amounts to $5.8 \AA$, the presence of Wat735 may explain the dramatically diminished yet still detectable $\mathrm{H}_{2}$ release activity of variant $\mathrm{S} 319 \mathrm{~A}_{\mathrm{CPI}}(6 \%)$.

The conformational differences between E279Q $\mathrm{CpI}$ and wildtype CpI are insignificant, except that the carboxamide group of Q279 $\mathrm{CpI}$ is slightly twisted relative to the original carboxyl group (Fig. 4). In the corresponding HydA1-variant E141Q, the glutamine residue precisely adopts the conformation of the glutamic acid residue in HydA1 wild type (Supplementary Fig. 5). For the corresponding alanine variant of both, HydA1 and CpI, shifts of the conserved water molecule in the putative PT pathway can be observed. While glutamine occupies the entire space of the native carboxyl group and thus clearly interrupts the putative PT pathway, an exchange to alanine may support additional $\mathrm{H}_{2} \mathrm{O}$ molecules to bridge the gap. However, in contrast to corresponding substitutions at the surface-exposed glutamate $\mathrm{E} 282_{\mathrm{CpI}}$, in neither E141 $\mathrm{A}_{\mathrm{HydA} 1}$ (Supplementary Fig. 5) nor E279A $\mathrm{ApI}^{25}$ (Fig. 4) additional $\mathrm{H}_{2} \mathrm{O}$ molecules are observed. This explains why exchanges of the median glutamate to either alanine or glutamine lead to residual activities of below 1\% (Fig. 1). 
In case of $\mathrm{C} 299 \mathrm{D}_{\mathrm{CpI}}$, the carboxyl group of the side chain establishes H-bonds $(2.7 \AA)$ with the amine group of $[2 \mathrm{Fe}]_{\mathrm{H}}$ and the "conserved" water molecule Wat708 (corresponding to Wat826 in chain $\mathrm{B}$ of $4 \mathrm{XDC}^{19}$ ) (Fig. 4). Unsurprisingly, protein samples of $\mathrm{C} 169 \mathrm{D}_{\mathrm{HydA} 1}$ and $\mathrm{C} 299 \mathrm{D}_{\mathrm{CpI}}$ both retain a rather high level of $\mathrm{H}_{2}$ release activity (30-80\%, Fig. 1). This is not the case when substituting cysteine for alanine, which for both enzymes leads to a complete loss of catalytic activity. Interestingly, the

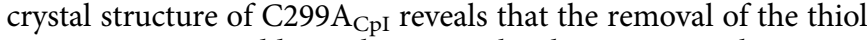
group causes an additional $\mathrm{H}_{2} \mathrm{O}$ molecule to occupy the vacant space. While the additional $\mathrm{H}_{2} \mathrm{O}$ is expected to rescue $\mathrm{PT}$ activity, it obviously does not restore enzymatic activity. A summary of the characteristic experimental data gained for each enzyme variant is presented in Supplementary Table 1.

\section{Discussion}

Fast proton transfer between bulk solvent and the $\mathrm{H}$-cluster is a precondition for the high catalytic turnover rates of [FeFe]hydrogenases. Mainly based on theoretical studies, four potential PT pathways have been discussed in literature ${ }^{15-18,20,37,38}$. The putative trajectory examined in this study has been favored as key catalytic PT pathway. However, unique experimental evidence for this assumption was lacking. A characterization of PT does not only help to understand the catalytic mechanism but will further contribute valuable parameters for the design of bio-inspired inorganic catalysts ${ }^{20}$. For artificial hydrogen catalysts, proton supply is often rate-limiting, e.g. due to the lack of a defined proton relay, thus making it necessary to add strong acids and adjust a very low solvent $\mathrm{pH}^{39}$. In this study, corresponding sets of SDM variants of $\mathrm{CpI}$ and HydA1 were generated to uncover the individual contribution of residues to PT in the putative PT pathway of $[\mathrm{FeFe}]$-hydrogenases ${ }^{25,40}$. The complementary data gained from $\mathrm{pH}$-activity profiles, crystal structure analysis, and ATR-FTIR spectroscopy unanimously show that the residues of this pathway are key for the supply and release of protons during catalytic turnover.

The crystal structures of wild-type CpI and its SDM variants reflect the $\mathrm{H}_{\mathrm{ox}}$ state ${ }^{19}$, which is commonly accepted to be the resting state of hydrogen turnover. To obtain a general survey on the putative hydrogen-bonding pattern in $\mathrm{H}_{\mathrm{ox}}$, the distances between consecutive PT partners in wild-type CpI and the nine SDM variants were derived from the corresponding structures (Fig. 5 and Supplementary Fig. 7). On the basis of CpI crystal structure $4 \mathrm{XDC}^{19}$, PROPKA empirically predicted $p \mathrm{Ka}$ values of 8.6 and 3.5 for E279 and E282, respectively $(\mathrm{pH} \mathrm{8})^{41}$. The relatively high $p \mathrm{Ka}$ of $\mathrm{E} 279_{\mathrm{CpI}}$ reflects its hydrophobic environment compared to the surface-exposed $\mathrm{E} 282_{\mathrm{CpI}}$ and suggests $\mathrm{E} 279_{\mathrm{CpI}}$ to be largely protonated while $\mathrm{E} 282_{\mathrm{CpI}}$ probably resides in the deprotonated state. Starting at the H-cluster, possible hydrogenbonding interactions can be assumed for adt-NH/C299 ${ }_{\mathrm{CPI}}$ and C299 ${ }_{\mathrm{CpI}} /$ Wat 826 , both of which exhibit comparatively large distances of 3.5 and $3.2 \AA^{42}$. Molecular dynamics simulations proposed a low H-bond occupancy between adt-NH and the thiol group of $\mathrm{C} 299_{\mathrm{CpI}}$ and a stronger contact between E282 $\mathrm{CpI}$ and R286 ${ }_{\mathrm{CPI}}$ to be preconditions for $\mathrm{H}_{2}$ oxidation starting from $\mathrm{H}_{\mathrm{ox}}{ }^{20}$. This proposal cannot be confirmed by our crystallographic data, which show the C299 thiol group in an intermediate orientation. However, we cannot rule out the possibility that such differences between theoretical data and structural information are influenced by the non-physiological crystallization conditions or low temperature crystal storage in liquid nitrogen, which might favor certain configurations in the PT pathway. The short distance of $2.5 \AA$ between Wat 826 and E279 $\mathrm{CpI}$ suggests a strong H-bond, in contrast to the adjoined pair $\mathrm{E} 279_{\mathrm{CpI}} / \mathrm{S} 319_{\mathrm{CpI}}$, for which a distance of $3.6 \AA$ again indicates a fairly weak interaction. The putative hydrogen bond between S319/E282 can be estimated to be of moderate strength $(2.9 \AA)$. E282 2 CpI potentially interacts with at least one surface-bound $\mathrm{H}_{2} \mathrm{O}$ molecule (Wat990). Finally, arginine $\mathrm{R} 286_{\mathrm{CpI}}$ (calculated $\mathrm{pKa}$ : 12.4) may serve as a putative salt bridge or hydrogen-bonding partner at close distance to E282 $2_{\mathrm{CpI}}(2.8 \AA)$. The combination of calculated $p \mathrm{~K}_{\mathrm{a}}$ values and $\mathrm{H}$ bond distances described in this study suggests for $\mathrm{H}_{\mathrm{ox}}$ the $\mathrm{H}$ bond pattern depicted in Fig. 5 .

Electron densities in the omit maps of crystal structures for wild-type CpI and most of the SDM variants examined here are unambiguously oriented (Fig. 6) and show low displacement factors (Supplementary Table 8). This is in contrast to quantum mechanics/molecular mechanics simulations by Long et al. ${ }^{38}$ who proposed a conformational bi-stability for the two glutamic acid residues E282 and E279 in the catalytic PT pathway. Our data rather favor a model in accordance with the Grotthuss mechanism, based on simultaneous deprotonation/protonation events according to a bucket line between strictly orientated residues and water molecules ${ }^{43}$. However, a bi-stability of the glutamate residues under turnover conditions might still be a valid interpretation, as it could also be regarded as switching between two different hydrogen-bonding patterns. In both cases, the direction of PT would be solely determined by the redox state of the $[2 \mathrm{Fe}]_{\mathrm{H}^{-}}$-cluster (see Supplementary Fig. 9 and Supplementary Discussion).

The FTIR data presented here were recorded under steadystate conditions applying changes in gas atmosphere and $\mathrm{pH}$. As protons are reactants in hydrogen turnover $\left(\mathrm{H}_{2} \rightleftharpoons 2 \mathrm{H}^{+}+2 \mathrm{e}^{-}\right)$, it

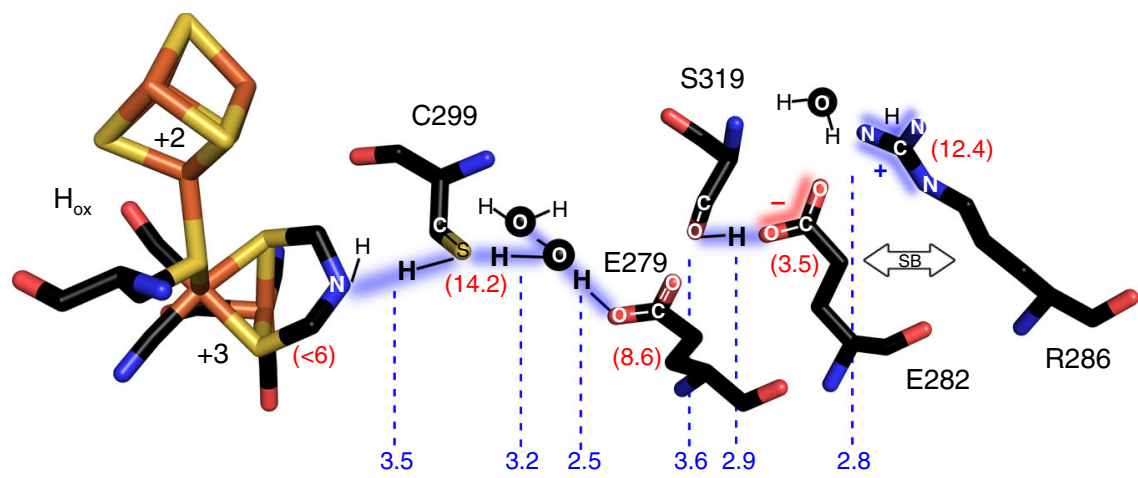

Fig. 5 Hydrogen-bonding pattern in the catalytic PT pathway of the $\mathrm{H}_{\mathrm{ox}}$ state. $\mathrm{H}$-bond pattern of $\mathrm{H}_{\mathrm{ox}}$ according to $p$ Ka values of the residues calculated for the structure of wild-type $\mathrm{Cpl}\left(4 \mathrm{XDC}^{19}\right)$ via PROPKA ${ }^{41}$ (see red numbers in parentheses). The $p K a$ of the adt-ligand in $\mathrm{H}_{\mathrm{ox}}$ is derived from a previous study $^{58}$. The blue numbers indicate the distances between neighboring positions of the PT pathway. The arrow labeled "SB" indicates a presumptive salt bridge contact between R286 and deprotonated E282 

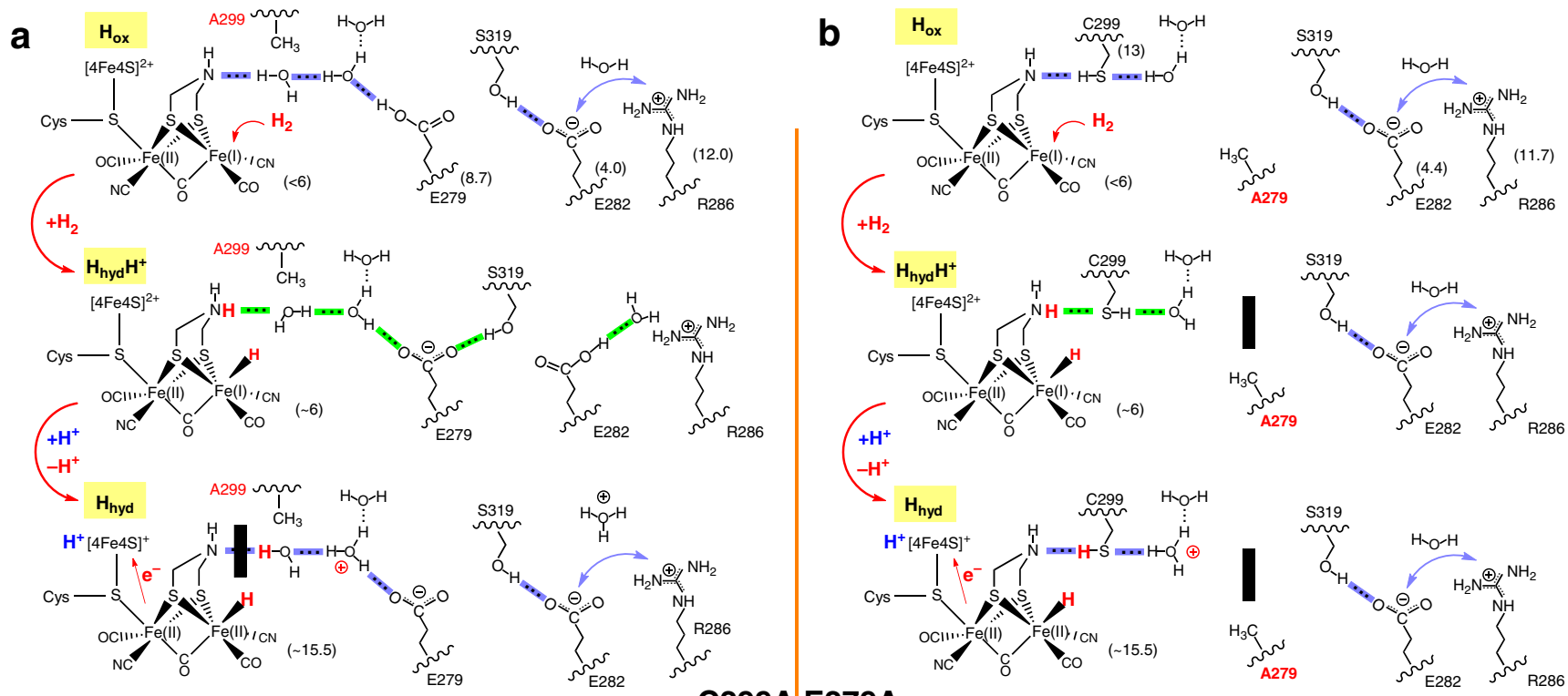

C299A E279A
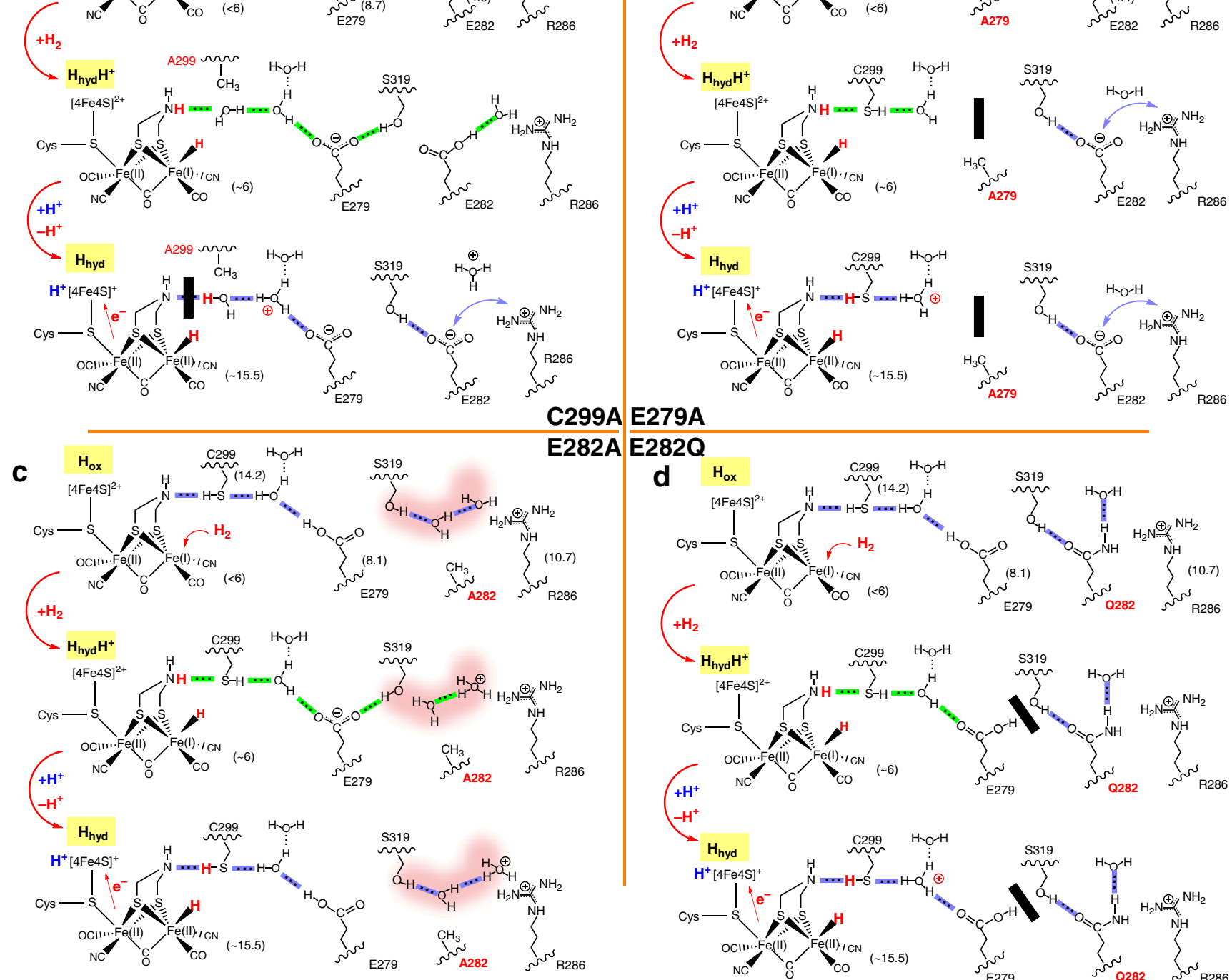

282A E282Q

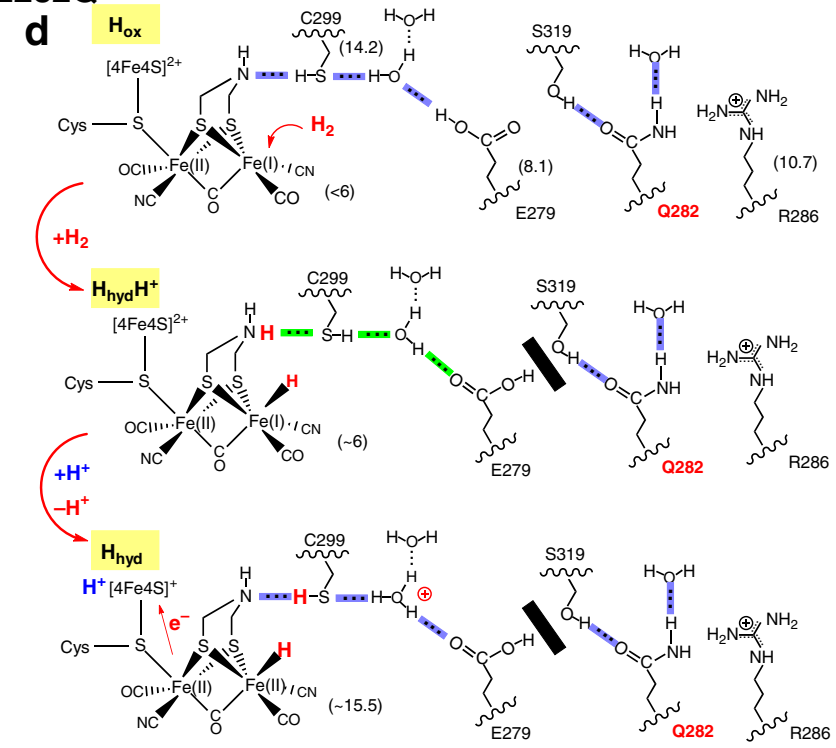

Fig. 6 Influence of SDM on the proton transfer mechanism during $\mathrm{H}_{2}$-uptake in Cpl. Effects of SDM on the proposed proton transfer mechanism for selected Cpl variants: C299A (a), E279A (b), E282A (c), and E282Q (d). $\mathrm{H}_{2}$-binding induces a shift in the $\mathrm{H}$-bond pattern (from mode 1 to mode 2 ) and initiates the catalytic mechanism during which the $\mathrm{H}$-bond pattern repeatedly shifts between modes 1 (blue) and 2 (green) while promoting a stepwise proton release via the PT pathway (for details see Supplementary Fig. 9+14). The $p K a$ values of adt-ligand at different redox states are derived from previous studies 49,58 . The mutated residues and hydrogen atoms from substrate were highlighted as red. The green double arrow indicates a putative salt bridge contact. In c (E282A), the pink shading area indicates a slowed-down but still functioning proton transfer. Protons presented in blue close to the $[4 \mathrm{Fe}]_{\mathrm{H}}$ sub-cluster originate from the recently described regulatory PT pathway $34,59,60$, which is independent of substrate/product transfer

is plausible to assume that mutagenesis in the catalytic PT pathway influences the equilibrium of $\mathrm{H}$-cluster species. This was exemplified above for those variants that accumulate $\mathrm{H}_{\text {hyd }}$. A similar effect on the dynamic equilibrium of catalytic states has been observed for $[\mathrm{NiFe}]$-hydrogenases ${ }^{44,45}$. The substitution of E17 for glutamine in the putative PT pathway of soluble hydrogenase I (SHI) of Pyrococcus furiosus disabled proton-coupled electron transfer (PCET) between two catalytic states $\left(\mathrm{Ni}_{\mathrm{a}}-\mathrm{C}\right.$ and $\left.\mathrm{Ni}_{\mathrm{a}}-\mathrm{S}\right)^{44}$, which was indicative by an accumulation of intermediates $\mathrm{Ni}_{\mathrm{a}}-\mathrm{I}^{1}$ and $\mathrm{Ni}_{\mathrm{a}}-\mathrm{I}^{2}$. For [FeFe]-hydrogenases, the hydride state has been demonstrated to accumulate under $\mathrm{H}_{2}$-oxidation conditions if proton efflux is severely restricted. This may be the result of an oversaturation of the native PT pathway due to the enhanced proton pressure, i.e. low bulk $\mathrm{pH}^{29,34}$. It can further be the result of $[2 \mathrm{Fe}]_{\mathrm{H}}$ derivatization or eliminating protonatable side chains in the catalytic PT pathway ${ }^{29}$. The hydride state has been shown to exhibit an uncharged azadithiolate ligand (adt$\mathrm{NH})^{37,46}$ that implies a transient intermediate with a protonated ammonium cation, e.g. as proposed by Reijerse et al. $\left(\mathrm{H}_{\mathrm{hyd}} \mathrm{H}^{+}\right)^{27}$. Accordingly, oxidation of $\mathrm{H}_{\text {hyd }}$ can be explained by PCET that relies on a functional release of protons. All PT pathway variants specifically react with $\mathrm{H}_{2}$ and it can be concluded that at least one proton is always injected into the hydrogen-bonding network, despite the compromised PT pathway. Single deprotonation appears possible as the next proton-binding site downstream C299 ${ }_{\text {CpI }}$ would be Wat826/Wat1120, which could form a Zundel- 
ion-like configuration upon protonation ${ }^{47}\left(\mathrm{H}_{5} \mathrm{O}_{2}{ }^{+}\right.$, Fig. 5 and Supplementary Fig. 12a). Neither of the two $\mathrm{H}_{2} \mathrm{O}$ molecules has been directly affected by mutagenesis. It may be concluded that PT is only blocked if a protonation of Wat $826 /$ Wat 1120 yield a Zundel-ion-like configuration, stabilized due to increased $p \mathrm{~K}_{\mathrm{a}}$ in comparison to $\mathrm{H}_{3} \mathrm{O}^{+}$.

The favorable position of the acidic asparagine side chain in the structure of $\mathrm{C} 299 \mathrm{D}_{\mathrm{CpI}}$ effectively connects adt-NH of the $[2 \mathrm{Fe}]_{\mathrm{H}}$ moiety with the conserved water molecule Wat708 in the otherwise intact PT pathway, rendering this variant significantly active. This comparatively high level of absolute activity and the fact that both corresponding variants, $\mathrm{C} 169 \mathrm{D}_{\mathrm{HydA} 1}$ and $\mathrm{C} 299 \mathrm{D}_{\mathrm{CpI}}$, exhibit significant shifts in their $\mathrm{pH}$-dependent activity optimum to the acidic range might explain why this type of variant refuses to accumulate $\mathrm{H}_{\text {hyd }}$ even at $\mathrm{pH}$ 4, while instead effectively continuing the turnover process as evident according to the comparatively dominant infrared bands for the reduced states $\mathrm{H}_{\text {red }}$ and $\mathrm{H}_{\text {sred }}\left(1890\right.$ and $1882 \mathrm{~cm}^{-1}$ for C169D) recorded at $\mathrm{pH} 4$ (see Supplementary Fig. 4). In case of variant $\mathrm{C} 299 \mathrm{~A}_{\mathrm{CpI}}$, the first deprotonation step $\left(\mathrm{H}_{\mathrm{hyd}} \mathrm{H}^{+} \rightleftharpoons \mathrm{H}_{\text {hyd }}+\mathrm{H}^{+}\right)$seems impossible but Fig. 3 shows that this variant very effectively accumulates $\mathrm{H}_{\text {hyd }}$ under $\mathrm{H}_{2}$. Thus, an alternative proton acceptor has to be assumed. The additional $\mathrm{H}_{2} \mathrm{O}$ molecule (Wat962), which is trapped in the space of the missing thiol group of variant C299A would be a plausible proton acceptor (Fig. 6 and Supplementary Fig. 13b). As it is well-positioned to bridge the adt-ligand (distance 3.4-3.7 $\AA$ ) and Wat826 (distance 3.6-3.7 $\AA$ ), it seems surprising that we are unable to measure any significant catalytic activity. This could be due to an unfavorable $p \mathrm{Ka}$ difference among the Zundel-ion-like complex, the uncharged adt-ligand and glutamic acid $\mathrm{E} 279_{\mathrm{Cp}}{ }^{48}$. The $p \mathrm{Ka}$ calculated for the adt-ligand in $\mathrm{H}_{\text {hyd }}$ is significantly larger than the one determined for $\mathrm{H}_{\mathrm{ox}}$ in mimics of the $[2 \mathrm{Fe}]_{\mathrm{H}}$-cluster ${ }^{49}$. However, no re-protonation of $\mathrm{H}_{\text {hyd }}$ is observed. We assume that the proton is trapped in a Zundel-ion-like configuration with a dangling $\mathrm{H}_{2} \mathrm{O}$ molecule Wat962 downstream of position A299 that prevents E279 from being re-protonated (Fig. 6a, C299A). Upon oxidation of $\mathrm{H}_{2}$, proton release via the $\mathrm{H}$-cluster may restrict re-protonation of $\mathrm{H}_{\text {hyd }}$ and steady-state accumulation of $\mathrm{H}_{\text {hyd }} \mathrm{H}^{+}$. Recently, an alanine was identified at the position homologous to C299 CpI in the newly described sensory [FeFe]-hydrogenase HydS of Thermotoga maritima, which showed very low $\mathrm{H}_{2}$ release and oxidation activities $(<5 \% \text { of HydA } 1)^{50}$. However, HydS is clearly more active than the $\mathrm{C} \rightarrow \mathrm{A}$ variants of $\mathrm{CpI}$ and HydA1 suggesting a slightly different situation for HydS. Nevertheless, the very low activity level of this sensory-type $[\mathrm{FeFe}]$-hydrogenase overall agrees very well with our results.

For variant $\mathrm{E} 279 \mathrm{~A}_{\mathrm{CpI}}$ the deprotonation of the $[2 \mathrm{Fe}]_{\mathrm{H}^{-}}$-cluster, which produces the hydride state would lead to the formation of the Zundel-ion-like configuration. However, due to the large distance between Wat 875 and S319 (up to $4.5 \AA$ ) the proton cannot proceed any further. As a consequence, $\mathrm{H}_{\text {hyd }}$ with its deprotonated adt- $\mathrm{NH}$ ligand would be stabilized in presence of $\mathrm{H}_{2}$ (Fig. 6b, E279A). In case of the corresponding exchange at the surface-exposed glutamate in $\mathrm{E} 282 \mathrm{~A}_{\mathrm{CpI}}$, two $\mathrm{H}_{2} \mathrm{O}$ molecules (chain B: Wat717 and Wat974) invading from the solvent are able to bridge the gap of the missing carboxyl group (Fig. 6c, E282A and Supplementary Fig. 13a) thereby rescuing a large fraction of $\mathrm{H}_{2}$-release activity $(\sim 50 \%)$. The fact that $\mathrm{E} 282 \mathrm{~A}_{\mathrm{CpI}}$ is rescued by an $\mathrm{H}_{2} \mathrm{O}$ moiety while in $\mathrm{E} 279 \mathrm{~A}_{\mathrm{CPI}}$ and $\mathrm{C} 299 \mathrm{~A}_{\mathrm{CPI}}$ the gap in the catalytic PT pathway cannot be closed, is probably connected to the superior accessibility at the protein surface and the specific functional requirements (such as e.g. $p \mathrm{Ka}$ ) of the position to be rescued within the PT pathway chain. This illustrates the significance of individual residues for the catalytic PT pathway, which appears to increase from surface to catalytic center.
However, the lack of $\mathrm{H}_{2}$ release activity resulting from the non-

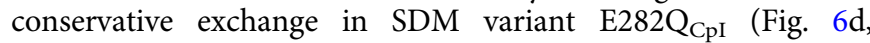
E282Q), which prohibits $\mathrm{H}_{2} \mathrm{O}$ access due to steric reasons demonstrates the necessity of a protonatable position at the entrance of the catalytic PT pathway (for SDM variants E279Q and S319A see Supplementary Figs. 10-11). Supplementary Table 9 provides a survey of the presumptive functions of all positions in the PT pathway, according to the conclusions drawn here.

The multilayered approach followed here, comprising enzyme kinetics, ATR-FTIR spectroscopy, and crystal-structure analysis, unambiguously verifies the herein proposed PT pathway to be the main trajectory for substrate/product transfer in [FeFe]-hydrogenases. From surface to active center the impact of substitutions along the PT pathway increases, with the inner part between E279 ${ }_{\mathrm{CpI}}$ and $\mathrm{C} 299_{\mathrm{CpI}}$ being the most vital positions for basic PT function. A model of the PT mechanism in line with the presented data further suggests a major role for the $\mathrm{H}_{2} \mathrm{O}$-cluster and a Zundel-ion-like configuration comprising Wat826 and Wat1120 in regulating PT pathway function. External $\mathrm{H}_{2} \mathrm{O}$ molecules can rescue PT function (1) if provided sufficient space and accessibility, (2) if gaps to neighboring PT pathway positions do not exceed H-bond distance $(\leq 4 \AA)$, and (3) if the overall $p \mathrm{Ka}$ gradient of the PT chain is not severely imbalanced. How PT is precisely coupled and synchronized with electron transfer between $[2 \mathrm{Fe}]_{\mathrm{H}}$ and $[4 \mathrm{Fe}]_{\mathrm{H}}$ remains to be further elucidated, possibly by a time-resolved characterization of the catalytic mechanism under sub-turnover conditions. The variants described here are dramatically slowed down in PT efficiency and provide excellent models to resolve the individual steps. In conclusion, the herein presented data give valuable insights into the molecular parameters that enable and tune PT in redox active proteins, thus providing useful guidelines for de novo catalyst design.

\section{Methods}

Site-directed mutagenesis. Expression constructs were generated using the QuikChange ${ }^{\circledast}$ Site-Directed Mutagenesis Kit from Stratagene using either pET21b$\mathrm{HydA1Cr}$ or pET21b-CpI as template and corresponding mismatch primers ${ }^{29}$, listed in Supplementary Table 6. The resulting constructs for the expression of SDM variants were verified via sequencing (3130xl Genetic Analyzer; Applied Biosystems) and used for the transformation of Escherichia coli expression host strain BL21 (DE3) $\Delta i s c R^{51}$, which was kindly provided by Patrik R. Jones.

Protein expression and maturation. Handling of expression cultures and enzyme variants was entirely done under strictly anaerobic conditions in a glove box (Coy laboratory) atmosphere of $98.5 \% \mathrm{~N}_{2}$ and $1.5 \% \mathrm{H}_{2}$. HydAl and $\mathrm{CpI}$ proteins were expressed in absence of maturases $\mathrm{HydE},-\mathrm{F}$, and $-\mathrm{G}^{52}$ as described previously and therefore lack the catalytically essential $[2 \mathrm{Fe}]_{\mathrm{H}}$ sub-cluster in the original state after purification. Cell disruption was achieved by ultrasonication. Cell debris was separated from the supernatant by ultracentrifugation and filtration (pore size $0.2 \mu \mathrm{m}$ ). Protein purification was done employing strep-tactin/strep-tag II (IBA GmbH) affinity chromatography. HydA1 and CpI apo-proteins were maturated in vitro by adding the synthetic mimic of the native $[2 \mathrm{Fe}]_{\mathrm{H}^{-}}$-complex $\left(\mathrm{Fe}_{2}\left[\mu-\left(\mathrm{SCH}_{2}\right)_{2} \mathrm{NH}\right](\mathrm{CN})_{2}(\mathrm{CO})_{4}\left[\mathrm{Et}_{4} \mathrm{~N}\right]_{2}\right)\left(\left[2 \mathrm{Fe}_{\mathrm{H}}\right]^{\mathrm{MIM}}\right)$ at a 10 -fold molar excess ${ }^{31}$ $\left[2 \mathrm{Fe}_{\mathrm{H}}\right]^{\mathrm{MIM}}$ was synthesized following literature procedures and kept in $100 \mathrm{mM}$ $\mathrm{K}_{2} \mathrm{HPO}_{4} / \mathrm{KH}_{2} \mathrm{PO}_{4}$ buffer ( $\mathrm{pH} 6.8$ ) at $-80{ }^{\circ} \mathrm{C}^{53}$. After an incubation period of $1 \mathrm{~h}$ at $25^{\circ} \mathrm{C}$, size-exclusion chromatography was employed to remove redundant complex, using NAP-5 columns (GE Healthcare), which were equilibrated with 100 $\mathrm{mM}$ Tris- $\mathrm{HCl}(\mathrm{pH} 8)$ containing $2 \mathrm{mM}$ sodium dithiolate (NaDT) prior to use. Proteins were concentrated using $30 \mathrm{kDa}$ Amicon Ultra centrifugal Filter units (Merck Millipore) and stored anaerobically at $-80^{\circ} \mathrm{C}$. SDS-polyacrylamide gel electrophoresis and Bradford assays were employed to verify protein purity and to calculate the resulting protein concentration.

Activity assays. $\mathrm{H}_{2}$-evolution rates of enzyme variants $(0.4-4 \mu \mathrm{g}$, depending on the level of residual activity) were determined employing a standard in vitro assay, comprising $100 \mathrm{mM} \mathrm{NaDT}$ as sacrificial electron donor and $10 \mathrm{mM}$ methyl viologen as electron mediator in $0.1 \mathrm{M} \mathrm{K}_{2} \mathrm{HPO}_{4} / \mathrm{KH}_{2} \mathrm{PO}_{4}, \mathrm{pH}$ 6.8. The reaction volume of $2 \mathrm{ml}$ was prepared in air-tight suba-seal vessels and purged with argon for $5 \mathrm{~min}$ prior to the $\mathrm{H}_{2}$-production period of $20 \mathrm{~min}$ in a shaking water bath, kept at $37^{\circ} \mathrm{C}$ 
The $\mathrm{H}_{2}$-production yield was determined by analyzing $400 \mu$ of the sample headspace via gas-chromatography (GC-2010, Shimadzu). For the determination of $\mathrm{pH}$ activity profiles, four different buffers were used and adjusted to individual $\mathrm{pH}$ values according to their respective buffer range, covering $\mathrm{pH}$ 5-10 with a resolution of 0.5 pH units: pH 5-6.5 (200 mM MES-NaOH, 2-(N-morpholino) ethanesulfonic acid); pH 7-7.5 (200 mM MOPS-NaOH, 3-( $\mathrm{N}$-morpholino) propanesulfonic acid); $\mathrm{pH} 8-9$ (200 mM Tris- $\mathrm{HCl})$; and pH 10 (200 mM CAPS- $\mathrm{NaOH}, \mathrm{N}$-cyclohexyl-3aminopropanesulfonic acid). $\mathrm{pH}$-dependent $\mathrm{H}_{2}$-uptake activity was monitored performing a colorimetric assay at $25^{\circ} \mathrm{C}$ with enzyme amounts between $0.5 \mathrm{ng}$ and $1 \mu \mathrm{g}$ in an atmosphere of 1 bar $\mathrm{H}_{2}$, using $10 \mathrm{mM}$ benzyl viologen (Sigma-Aldrich) as electron acceptor $\left(\varepsilon_{600}: 10 \mathrm{mM}^{-1} \mathrm{~cm}^{-1}\right)^{6}$.

\section{Crystallization and structural determination of variants. Vapor diffusion} hanging drop and sitting drop methods were applied under anaerobic conditions at $277 \mathrm{~K}$ to crystallize the SDM variants using protein concentrations between 10 and $15 \mathrm{mg} \mathrm{ml}^{-1}$. Details of the crystallization conditions are summarized in Supplementary Table 3. Mounting was carried out after 5-10 days of crystal growth and crystals selected for data collection were flash-frozen and stored in liquid $\mathrm{N}_{2}$. Diffraction data were collected at $100 \mathrm{~K}$ in different beamlines as indicated in Supplementary Table 3 and processed using $\mathrm{XDS}^{54}$. Phenix ${ }^{55}$ and $\operatorname{Coot}^{56}$ were employed for molecular replacement (starting models for CpI and HydA1 were $4 \mathrm{XDC}^{19}$ and $3 \mathrm{LX} 4^{36}$ respectively) and structural refinement. The details of crystallographic data gained for each of the variants are summarized in Supplementary Table 4 .

Infrared spectroscopy. Wild-type and SDM variants of HydA1 and CpI were probed by in situ ATR-FTIR spectroscopy $29,34,57$ using a rapid-scan Tensor 27 spectrometer (Bruker Optik, Germany) equipped with a three-reflection $\mathrm{ZnSe} /$ silicon crystal ATR cell (Smith Detection, USA). The spectrometer was kept under anaerobic conditions in a vinyl glove box (Coy Laboratories, USA) under a waterfree atmosphere of $99 \% \mathrm{~N}_{2}$ and $1 \% \mathrm{H}_{2}$. All experiments were performed at room temperature, on hydrated films and in the dark. The oxidized state $\mathrm{H}_{\mathrm{ox}}$ was populated under $100 \% \mathrm{~N}_{2}$ ambient partial pressure while the reduced states $\left(\mathrm{H}_{\text {red }} /\right.$ $\mathrm{H}_{\text {sred }}, \mathrm{H}_{\text {red }}$, and $\mathrm{H}_{\text {hyd }}$ ) were observed in the presence of $\mathrm{H}_{2}$ exclusively. All spectra shown in Fig. 3 were mathematically corrected for the broad combination band of liquid $\mathrm{H}_{2} \mathrm{O}$ at around $2120 \mathrm{~cm}^{-1}$ and normalized to unity.

Reporting Summary. Further information on research design is available in the Nature Research Reporting Summary linked to this article.

\section{Data availability}

The coordinates and structure factors for all structures are deposited in the PDB as 6GLY, 6GLZ, 6GM0, 6GM1, 6GM2, 6GM3, 6GM4, 6GM5, 6GM6, 6GM7, and 6GM8. Further data supporting findings of this study are available from the corresponding authors upon reasonable request. A Reporting Summary for this Article is available as a Supplementary Information file.

Received: 25 June 2018 Accepted: 18 October 2018

Published online: 09 November 2018

\section{References}

1. Frey, M. Hydrogenases: hydrogen-activating enzymes. ChemBioChem 3 , 153-160 (2002).

2. Vignais, P. M. \& Billoud, B. Occurrence, classification, and biological function of hydrogenases: an overview. Chem. Rev. 107, 4206-4272 (2007).

3. Vignais, P. M., Billoud, B. \& Meyer, J. Classification and phylogeny of hydrogenases. FEMS Microbiol. Rev. 25, 455-501 (2001).

4. Lubitz, W., Ogata, H., Rüdiger, O. \& Reijerse, E. Hydrogenases. Chem. Rev 114, 4081-4148 (2014).

5. Krassen, H. et al. Immobilization of the [FeFe]-hydrogenase CrHydAl on a gold electrode: design of a catalytic surface for the production of molecular hydrogen. J. Biotechnol. 142, 3-9 (2009).

6. Lampret, $\mathrm{O}$. et al. Interplay between the $\mathrm{CN}^{-}$ligands and the secondary coordination sphere of the $\mathrm{H}$-cluster in [FeFe]-hydrogenases. J. Am. Chem. Soc. 139, 18222-18230 (2017).

7. Gloaguen, F., Lawrence, J. D., Schmidt, M., Wilson, S. R. \& Rauchfuss, T. B. Synthetic and structural studies on $\left[\mathrm{Fe}_{2}(\mathrm{SR})_{2}(\mathrm{CN})_{\mathrm{x}}(\mathrm{CO})_{6-\mathrm{x}}\right]^{\mathrm{x}-\text { as active }}$ site models for Fe-only hydrogenases. J. Am. Chem. Soc. 123, 12518-12527 (2001).

8. Hexter, S. V., Grey, F., Happe, T., Climent, V. \& Armstrong, F. A. Electrocatalytic mechanism of reversible hydrogen cycling by enzymes and distinctions between the major classes of hydrogenases. Proc. Natl Acad. Sci. USA 109, 11516-11521 (2012).
9. Takahashi, E. \& Wraight, C. A. Small weak acids reactivate proton transfer in reaction centers from Rhodobacter sphaeroides mutated at AspL210 and AspM17. J. Biol. Chem. 281, 4413-4422 (2006).

10. Chang, Y. H., Chuang, L. Y. \& Hwang, C. C. Mechanism of proton transfer in the 3a-hydroxysteroid dehydrogenase/carbonyl reductase from Comamonas testosteroni. J. Biol. Chem. 282, 34306-34314 (2007).

11. Whitehead, S. J., Iwaki, M., Cotton, N. P., Rich, P. R. \& Jackson, J. B. Inhibition of proton-transfer steps in transhydrogenase by transition metal ions. Biochim. Biophys. Acta 1787, 1276-1288 (2009).

12. Faxen, K., Salomonsson, L., Adelroth, P. \& Brzezinski, P. Inhibition of proton pumping by zinc ions during specific reaction steps in cytochrome $\mathrm{c}$ oxidase. Biochim. Biophys. Acta 1757, 388-394 (2006).

13. Garczarek, F. \& Gerwert, K. Functional waters in intraprotein proton transfer monitored by FTIR difference spectroscopy. Nature 439, 109-112 (2006).

14. Gerwert, K., Freier, E. \& Wolf, S. The role of protein-bound water molecules in microbial rhodopsins. Biochim. Biophys. Acta 1837, 606-613 (2014).

15. Cornish, A. J., Gärtner, K., Yang, H., Peters, J. W. \& Hegg, E. L. Mechanism of proton transfer in [FeFe]-hydrogenase from Clostridium pasteurianum. J. Biol. Chem. 286, 38341-38347 (2011).

16. Hong, G., Cornish, A., Hegg, E. \& Pachter, R. On understanding proton transfer to the biocatalytic $[\mathrm{Fe}-\mathrm{Fe}]_{\mathrm{H}}$ sub-cluster in $[\mathrm{Fe}-\mathrm{Fe}] \mathrm{H}_{2}$ ases: $\mathrm{QM} / \mathrm{MM}$ MD simulations. Biochim. Biophys. Acta 1807, 510-517 (2011).

17. Nicolet, Y., Piras, C., Legrand, P., Hatchikian, C. E. \& Fontecilla-Camps, J. C. Desulfovibrio desulfuricans iron hydrogenase: the structure shows unusual coordination to an active site Fe binuclear center. Structure 7, 13-23 (1999).

18. Sode, O. \& Voth, G. A. Electron transfer activation of a second water channel for proton transport in [FeFe]-hydrogenase. J. Chem. Phys. 141, 22D572 (2014).

19. Esselborn, J. et al. A structural view of synthetic cofactor integration into [FeFe]-hydrogenases. Chem. Sci. 7, 959-968 (2016).

20. Ginovska-Pangovska, B. et al. Molecular dynamics study of the proposed proton transport pathways in [FeFe]-hydrogenase. Biochim. Biophys. Acta 1837, 131-138 (2014).

21. Berggren, G. et al. Biomimetic assembly and activation of [FeFe]hydrogenases. Nature 499, 66-69 (2013).

22. Cornish, A. J. et al. Single-amino acid modifications reveal additional controls on the proton pathway of [FeFe]-hydrogenase. Biochemistry 55, 3165-3173 (2016).

23. Morra, S. et al. Site saturation mutagenesis demonstrates a central role for cysteine 298 as proton donor to the catalytic site in CaHydA [FeFe]hydrogenase. PLoS ONE 7, e48400 (2012).

24. Morra, S. et al. The effect of a C298D mutation in CaHydA [FeFe]hydrogenase: insights into the protein-metal cluster interaction by EPR and FTIR spectroscopic investigation. Biochim. Biophys. Acta 1857, 98-106 (2016).

25. Winkler, M., Esselborn, J. \& Happe, T. Molecular basis of [FeFe]-hydrogenase function: An insight into the complex interplay between protein and catalytic cofactor. Biochim. Biophys. Acta 1827, 974-985 (2013).

26. Mulder, D. W., Guo, Y., Ratzloff, M. W. \& King, P. W. Identification of a catalytic iron-hydride at the H-cluster of [FeFe]-hydrogenase. J. Am. Chem. Soc. 139, 83-86 (2017).

27. Reijerse, E. J. et al. Direct observation of an iron-bound terminal hydride in [FeFe]-hydrogenase by nuclear resonance vibrational spectroscopy. J. Am. Chem. Soc. 139, 4306-4309 (2017).

28. Rumpel, S., Sommer, C., Reijerse, E., Fares, C. \& Lubitz, W. Direct detection of the terminal hydride intermediate in [FeFe] Hydrogenase by NMR spectroscopy. J. Am. Chem. Soc. 140, 3863-3866 (2018).

29. Winkler, M. et al. Accumulating the hydride state in the catalytic cycle of [FeFe]-hydrogenases. Nat. Commun. 8, 16115 (2017).

30. Cramer, S. P. et al. Terminal hydride species in $[\mathrm{FeFe}]$-hydrogenases are vibrationally coupled to the active site environment. Angew. Chem. Int. Ed. 130, 10765-10769 (2018)

31. Esselborn, J. et al. Spontaneous activation of [FeFe]-hydrogenases by an inorganic $[2 \mathrm{Fe}]$ active site mimic. Nat. Chem. Biol. 9, 607-609 (2013).

32. Noth, J. et al. [FeFe]-Hydrogenase with chalcogenide substitutions at the $\mathrm{H}-$ cluster maintains full $\mathrm{H}_{2}$ evolution activity. Angew. Chem. Int. Ed. 128, 8536-8540 (2016).

33. Noth, J. et al. Lyophilization protects $[\mathrm{FeFe}]$-hydrogenases against $\mathrm{O}_{2}$-induced H-cluster degradation. Sci. Rep. 5, 13978 (2015).

34. Senger, $\mathrm{M}$. et al. Protonation/reduction dynamics at the [4Fe-4S] cluster of the hydrogen-forming cofactor in [FeFe]-hydrogenases. Phys. Chem. Chem. Phys. 20, 3128-3140 (2018).

35. Mebs, S. et al. Bridging hydride at reduced H-cluster species in [FeFe]Hydrogenases revealed by infrared spectroscopy, isotope editing, and quantum Chemistry. J. Am. Chem. Soc. 139, 12157-12160 (2017).

36. Mulder, D. W. et al. Stepwise [FeFe]-hydrogenase $\mathrm{H}-$ cluster assembly revealed in the structure of $\mathrm{HydA}^{\Delta \mathrm{EFG}}$. Nature 465, 248-251 (2010). 
37. Mulder, D. W. et al. Investigations on the role of proton-coupled electron transfer in hydrogen activation by [FeFe]-hydrogenase. J. Am. Chem. Soc. 136, 15394-15402 (2014).

38. Long, H., King, P. W. \& Chang, C. H. Proton transport in Clostridium pasteurianum $[\mathrm{FeFe}]$ hydrogenase I: a computational study. J. Phys. Chem. B 118, 890-900 (2014).

39. Wang, N., Wang, M., Chen, L. \& Sun, L. Reactions of [FeFe]-hydrogenase models involving the formation of hydrides related to proton reduction and hydrogen oxidation. Dalton. Trans. 42, 12059-12071 (2013).

40. Meyer, J. [FeFe] hydrogenases and their evolution: a genomic perspective. Cell. Mol. Life Sci. 64, 1063 (2007).

41. Olsson, M. H., Søndergaard, C. R., Rostkowski, M. \& Jensen, J. H. PROPKA3: consistent treatment of internal and surface residues in empirical $\mathrm{pKa}$ predictions. J. Chem. Theory Comput. 7, 525-537 (2011).

42. Jeffrey, G. A. An Introduction to Hydrogen Bonding (Oxford Univ. Press, New York, 1997).

43. Cukierman, S. Et tu, Grotthuss! and other unfinished stories. Biochim. Biophys. Acta 1757, 876-885 (2006).

44. Greene, B. L., Vansuch, G. E., Wu, C.-H., Adams, M. W. \& Dyer, R. B. Glutamate gated proton-coupled electron transfer activity of a [NiFe]Hydrogenase. J. Am. Chem. Soc. 138, 13013-13021 (2016).

45. Evans, R. M. et al. Mechanistic exploitation of a self-repairing, blocked proton transfer pathway in an $\mathrm{O}_{2}$-tolerant [NiFe]-Hydrogenase. J. Am. Chem. Soc. 140, 10208-10220 (2018)

46. Pelmenschikov, V. et al. Reaction coordinate leading to $\mathrm{H}_{2}$ production in [FeFe]-Hydrogenase identified by nuclear resonance vibrational spectroscopy and density functional theory. J. Am. Chem. Soc. 139, 16894-16902 (2017).

47. Zundel, G. \& Metzger, H. Energiebänder der tunnelnden überschuß-protonen in flüssigen säuren. Eine IR-spektroskopische untersuchung der natur der gruppierungen $\mathrm{H}_{5} \mathrm{O}_{2}{ }^{+}$. Z. Phys. Chem. 58, 225-245 (1968).

48. Linke, K. \& Ho, F. M. Water in Photosystem II: structural, functional and mechanistic considerations. Biochim. Biophys. Acta 1837, 14-32 (2014).

49. Huynh, M. T., Wang, W., Rauchfuss, T. B. \& Hammes-Schiffer, S. Computational investigation of [FeFe]-hydrogenase models: characterization of singly and doubly protonated intermediates and mechanistic Insights. Inorg. Chem. 53, 10301-10311 (2014).

50. Chongdar, N. et al. Unique spectroscopic properties of the H-cluster in a putative sensory [FeFe] hydrogenase. J. Am. Chem. Soc. 140, 1057-1068 (2018).

51. Akhtar, M. K. \& Jones, P. R. Deletion of iscR stimulates recombinant clostridial $\mathrm{Fe}-\mathrm{Fe}$ hydrogenase activity and $\mathrm{H}_{2}$-accumulation in Escherichia coli BL21 (DE3). Appl. Microbiol. Biotechnol. 78, 853-862 (2008).

52. Kuchenreuther, J. M. et al. High-yield expression of heterologous [FeFe] hydrogenases in Escherichia coli. PLoS ONE 5, e15491 (2010).

53. Li, H. \& Rauchfuss, T. B. Iron carbonyl sulfides, formaldehyde, and amines condense to give the proposed azadithiolate cofactor of the Fe-only hydrogenases. J. Am. Chem. Soc. 124, 726-727 (2002).

54. Kabsch, W. XDS. Acta Crystallogr. D. 66, 125-132 (2010).

55. Adams, P. D. et al. PHENIX: a comprehensive Python-based system for macromolecular structure solution. Acta Crystallogr. D. 66, 213-221 (2010).

56. Emsley, P. \& Cowtan, K. Coot: model-building tools for molecular graphics. Acta Crystallogr. D. 60, 2126-2132 (2004).

57. Senger, M. et al. Stepwise isotope editing of [FeFe]-hydrogenases exposes cofactor dynamics. Proc. Natl Acad. Sci. USA 113, 8454-8459 (2016).

58. Sommer, C. et al. Proton coupled electronic rearrangement within the $\mathrm{H}$ cluster as an essential step in the catalytic cycle of [FeFe] hydrogenases. J. Am. Chem. Soc. 139, 1440-1443 (2017).
59. Mebs, S. et al. Hydrogen and oxygen trapping at the H-cluster of [FeFe]hydrogenase revealed by site-selective spectroscopy and QM/MM calculations. Biochim. Biophys. Acta 1859, 28-41 (2018).

60. Haumann, M. \& Stripp, S. T. The molecular proceedings of biological hydrogen turnover. Acc. Chem. Res. 51, 1755-1763 (2018).

\section{Acknowledgements}

M.W. and T.H. gratefully acknowledge financial support from the VolkswagenStiftung (Design of [FeS]-cluster containing Metallo-DNAzymes (Az 93412)) Deutsche Forschungsgemeinschaft (DFG) (the Cluster of Excellence RESOLV EXC1069 and GRK 2341: Microbial Substrate Conversion). J.D. acknowledges support by the China Scholarship Council (CSC) and DFG-EXC1069. M.S. and S.T.S thank the International Max Plank Research School (IMPRS) on Multiscale Biosystems and the Focus Area NanoScale (Freie Universität Berlin) for financial support U.-P.A. and F.W. are grateful for financial support by the Deutsche Forschungsgemeinschaft (Emmy Noether grant to U.-P.A., AP242/2-1) and the Fraunhofer Internal Programs (Attract 097-602175). F.W. further thanks the Studienstiftung des deutschen Volkes for a PhD fellowship. We thank the staff of beamlines ID23-1 and BM30A at the ESRF and PXII at the SLS for technical support during X-ray data collection.

\section{Author contributions}

M.W. and T.H. designed the research. M.W., J.D., S.T.S., and M.S. wrote the manuscript. J.D. expressed, purified, and maturated the proteins and biochemically characterized them. J.D., J.E., V.E., and E.H. performed protein crystallization and structural analysis. M.S. and S.T.S. were responsible for infrared spectroscopy part. F.W. and U.-P.A. synthesized the $[2 \mathrm{Fe}]_{\mathrm{H}}$ complex.

\section{Additional information}

Supplementary Information accompanies this paper at https://doi.org/10.1038/s41467018-07140-x.

Competing interests: The authors declare no competing interests.

Reprints and permission information is available online at http://npg.nature.com/ reprintsandpermissions/

Publisher's note: Springer Nature remains neutral with regard to jurisdictional claims in published maps and institutional affiliations.

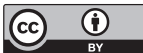

Open Access This article is licensed under a Creative Commons Attribution 4.0 International License, which permits use, sharing, adaptation, distribution and reproduction in any medium or format, as long as you give appropriate credit to the original author(s) and the source, provide a link to the Creative Commons license, and indicate if changes were made. The images or other third party material in this article are included in the article's Creative Commons license, unless indicated otherwise in a credit line to the material. If material is not included in the article's Creative Commons license and your intended use is not permitted by statutory regulation or exceeds the permitted use, you will need to obtain permission directly from the copyright holder. To view a copy of this license, visit http://creativecommons.org/ licenses/by/4.0/.
\end{abstract}

(C) The Author(s) 2018 